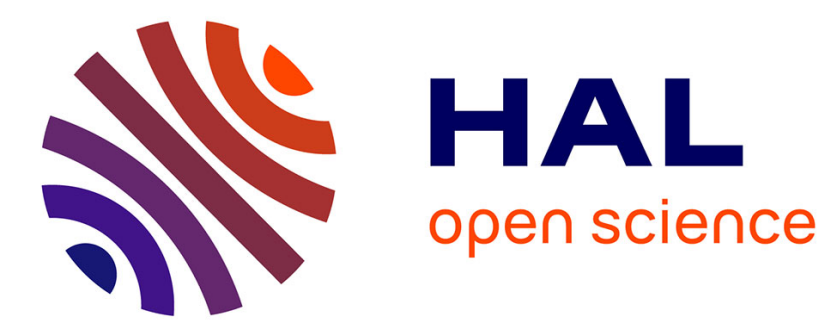

\title{
Synthesis of iron oxide nanoparticles in a microfluidic device: preliminary results in a coaxial flow millichannel
}

Ali Abou Hassan, Olivier Sandre, Valérie Cabuil, Patrick Tabeling

\section{To cite this version:}

Ali Abou Hassan, Olivier Sandre, Valérie Cabuil, Patrick Tabeling. Synthesis of iron oxide nanoparticles in a microfluidic device: preliminary results in a coaxial flow millichannel. Chemical Communications, 2008, 15, pp.1783-1785. 10.1039/b719550h . hal-00266423

\section{HAL Id: hal-00266423 \\ https://hal.science/hal-00266423}

Submitted on 26 May 2019

HAL is a multi-disciplinary open access archive for the deposit and dissemination of scientific research documents, whether they are published or not. The documents may come from teaching and research institutions in France or abroad, or from public or private research centers.
L'archive ouverte pluridisciplinaire HAL, est destinée au dépôt et à la diffusion de documents scientifiques de niveau recherche, publiés ou non, émanant des établissements d'enseignement et de recherche français ou étrangers, des laboratoires publics ou privés. 
Graphical and textural abstract

The synthesis of stable and magnetic colloidal iron oxide nanoparticles by coprecipitation of $\mathrm{Fe}(\mathrm{II})$ and $\mathrm{Fe}(\mathrm{III})$ by $\mathrm{TMAOH}$ in a millichannel is described.

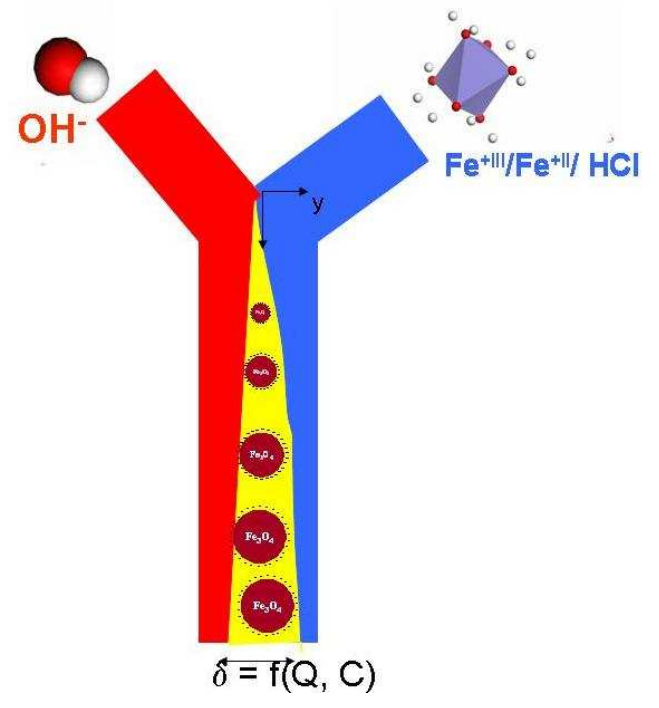




\title{
Synthesis of iron oxide nanoparticles in a microfluidic device: preliminary results in a coaxial flow millichannel
}

\author{
Ali Abou Hassan, $*^{a}$ Olivier Sandre $^{a}$, Valérie Cabuil ${ }^{a}$ and Patrick Tabeling ${ }^{b}$ \\ Received (in Cambridge, UK) 19th December 2007, Accepted 24th January 2008 \\ First published on the web 28th February 2008 \\ https://dx.doi.org/10.1039/b719550h
}

\begin{abstract}
5 A millimetric coaxial flow device operating under laminar flow has been designed to study the synthesis of iron oxide nanoparticles in a millichannel. The flow rate of the different reagents has been adjusted all over the experiments so that magnetic and stable colloidal iron oxide particles with a size less 10 than $7 \mathbf{~ n m}$ have been prepared continuously.
\end{abstract}

Miniaturization of chemical reactions and the development of "lab on a chip" (LOC) technology has gained significant importance in the recent years. ${ }^{1}$ One predicts indeed that small dimensions of vessels lowers the diffusion times of chemical 15 species, so that mass transport is improved in microstructured reactors. ${ }^{2}$ Scaling down reactors dimensions is proposed as an opportunity to improve size and composition control in the field of materials synthesis. ${ }^{3}$ Local variations in reaction conditions such as concentration and temperature are 20 minimized and therefore control of both nucleation and particle growth can be used to improve monodispersity in nanoparticles synthesis. ${ }^{4}$

As an example, the synthesis of iron oxides nanoparticles has attracted much attention motivated by their wide range of 25 applications. Colloidal iron oxides are used as single bitelements in high density magnetic data storage arrays, ${ }^{5}$ ionic ferrofluids, ${ }^{6}$ and in the biomedical field for example as contrast enhancement agents for Magnetic Resonance Imaging, ${ }^{7}$ or for hyperthermia, ${ }^{8}$ etc... Because the properties 30 of these nanocrystals strongly depend on their dimension, the synthesis of monodisperse nanoparticles is one of the most challenging problems. ${ }^{4}$ At the beginning of the 1950's V. K. Lamer proposed a mechanism based on a nucleation-growth process to describe the synthesis of nanoparticles. ${ }^{5,} 6$ Since 35 then, various chemical synthetic strategies have been reported to obtain monodisperse nanoparticles with different shapes. ${ }^{10}$ Recently, several groups designed microreactors and reported the improvement of inorganic and metallic nanoparticles synthesis. However the synthesis of inorganic materials has 40 been focused on Quantum Dots as $\mathrm{CdS}^{11}$ or $\mathrm{CdSe}^{12}$, silica, ${ }^{13}$ titania, ${ }^{14}$ and titania/silica core-shell colloidal nanoparticles. ${ }^{15}$ There has been until now no reported study of the synthesis in microchannels of colloidal iron oxide nanoparticles from the following alakaline coprecipitation reaction:

${ }_{45} \mathrm{Fe}^{2+}{ }_{(\mathrm{aq})}+2 \mathrm{Fe}^{3+}{ }_{(\mathrm{aq})}+8 \mathrm{OH}_{(\mathrm{aq})}^{-} \rightarrow \mathrm{Fe}_{3} \mathrm{O}_{4(\mathrm{~s})}+4 \mathrm{H}_{2} \mathrm{O}_{(\mathrm{l})}$

For this purpose, we designed a $3 \mathrm{D}$ millifluidic device performing the mixing of two coaxial flows of miscible fluids (Fig. 1), one containing the iron "precursor salts", the other a strong base. The length of the capillary from the confluence

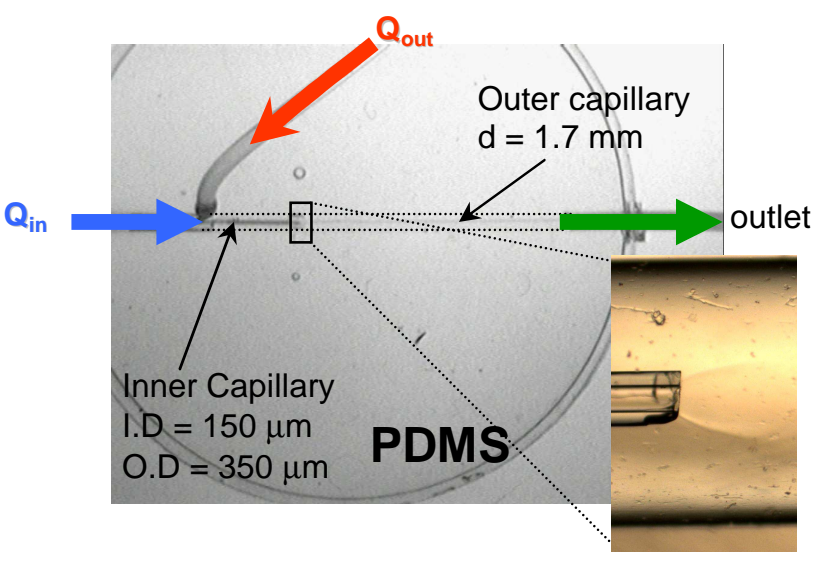

Fig. 1 Coaxial flows device operating under laminar regime. The inset image shows the outlet of the inner capillary with the solution of iron + II and iron +III flowing into the stream of TMAOH alkaline solution.

region to the outlet is $3 \mathrm{~cm}$. A (poly) tetrafluoroethylene 55 (PTFE) tube $(500 \mu \mathrm{m} \mathrm{ID}$ and $10 \mathrm{~cm}$ long) leading to a sample vial was connected to the reactor outlet. Depending on the two flow rates $Q_{\text {in }}$ and $Q_{\text {out }}$, the residence times range between 10 and $48 \mathrm{sec}$. The outer capillary with $1.7 \mathrm{~mm}$ diameter $(\mathrm{d})$ was shaped by the molding of a cylindrical tubing (Upchurch ${ }_{60}$ Scientific) in a Petri dish with Polydimethl siloxane (PDMS, Sylgard 184) and subsequent removal when the resin is cured. The central capillary with $150 \mu \mathrm{m}$ of inner diameter (I.D.), $360 \mu \mathrm{m}$ of outer diameter (O.D.) was obtained by fixing a glass capillary (Plymicro $^{\circledR}$, usually used for Capillary ${ }_{65}$ Electrophoresis) inside the tip of a micropipette (Gilson), which conical shape enables a precise centering. By comparison with a 2D flow focusing device (i.e. a typical "Yshaped" channel), the 3D coaxial flows setup offers two main advantages: on the one hand, it enables a precision 70 positionning of the "precursors" flow at the centre of the channel in both longitudinal and lateral dimensions and on the other hand, it avoids adsorption of any precipitate species onto the PDMS walls which are totally wetted by the alkaline outer flow.

75 A solution of total iron salts concentration $\mathrm{c}=10^{-2} \mathrm{~mol} / \mathrm{L}$ with 0.5 as molar ratio $\mathrm{Fe}(\mathrm{II}) / \mathrm{Fe}(\mathrm{III})$ was prepared by mixing $\mathrm{FeCl}_{3}$ and "fresh" $\mathrm{FeCl}_{2}, 4 \mathrm{H}_{2} \mathrm{O}$ salts in diluted and degased hydrochloric acid $(\mathrm{pH} \sim 0.4)$. Diluted hydrochloric acid was used as $\mathrm{Fe}(\mathrm{II})$ ions are more stable in acidic medium so non 80 iron hydroxide can precipitate. The tetramethylammonium hydroxide $\left(\left(\mathrm{CH}_{3}\right)_{4} \mathrm{NOH}, \mathrm{TMAOH}\right)$ at a concentration 0.172 $\mathrm{mol} / \mathrm{L}$ was the alkaline solution. Both solutions were injected 
into the channel through two syringes actuated automatically (Harvard apparatus), the iron "precursors" solution was pumped into the inner capillary and the TMAOH base into the outer capillary of the channel. TMAOH was chosen prior to 5 any other base as the $\mathrm{TMA}^{+}$cations afford enhanced stability of colloidal oxide dispersion. ${ }^{16}$

The volumetric rate flows of both solutions (respectively $\mathrm{Q}_{\text {in }}$ and $\left.\mathrm{Q}_{\text {out }}\right)$ were ajusted to avoid any turbulent vortex in the capillary. ${ }^{17}$ Owing to the laminar regime in the channel, 10 mixing is controlled by the diffusion of species. ${ }^{18}$ The diffusion of iron complexes in aqueous solution is much slower than the diffusion of hydroxide ions $\mathrm{OH}^{-}$and of the protons $\mathrm{H}^{+}$. The diffusion coefficient (D) is almost $1 \times 10^{-9}$ $\mathrm{m}^{2} / \mathrm{s}$ for a single iron complex as $\left[\mathrm{Fe}\left(\mathrm{OH}_{2}\right)_{6}\right]^{2 / 3+} 19,20$ 15 compared to $\mathrm{D} \sim 5.3 \times 10^{-9} \mathrm{~m}^{2} / \mathrm{s}$ for $\mathrm{OH}^{-}$and $\mathrm{D} \sim 9.31 \times 10^{-9} \mathrm{~m}^{2} /$ for $\mathrm{H}^{+21}$ at $25^{\circ} \mathrm{C}$ in diluted solutions. Thus, the diffusion of iron complexes from the central acidic stream into the peripheral TMAOH stream flow is disregarded. On the contrary, the fast diffusion of $\mathrm{H}^{+}$and $\mathrm{OH}^{-}$leads to the prediction that the $\mathrm{pH}$ 20 varies continuously from acidic in the central flow to basic at the periphery, the $\mathrm{pH}$ gradient being progressively smoothed out when moving towards the outlet of the channel. The coprecipitation reaction will therefore be likely confined in the neutral region near the channel centre. The excess of 25 TMAOH will allow the dispersion of the particles after their synthesis, and avoid their adsorption onto the walls. The particles will be collected at the outlet without any problem of plugging. In order to stabilize the inner flow of iron solution before initiating the hydrolysis, we injected at first a $\mathrm{HCl}$ 30 solution of same $\mathrm{pH} \sim 0.4$ in the outer stream. The outer flow is then switched to TMAOH solution. A few seconds after the outlet (time across the PTFE tubing), the reaction was "quenched" by fast solvant extraction to prevent any ageing of the nanoparticles in the aqueous solution. In practical, the 35 collection vial containing a cationic surfactant didodecyldimethyl ammonium bromide $\left(\mathrm{C}_{26} \mathrm{H}_{56} \mathrm{BrN}\right.$, DDAB, $\left.\mathrm{C}=0.02 \mathrm{M}\right)$ in cyclohexane was stirred at around $200 \mathrm{rpm}$ with a glass helix stirrer. ${ }^{22}$ A stable colloidal suspension of nanoparticles coated by DDAB is obtained in the cyclohexane phase.

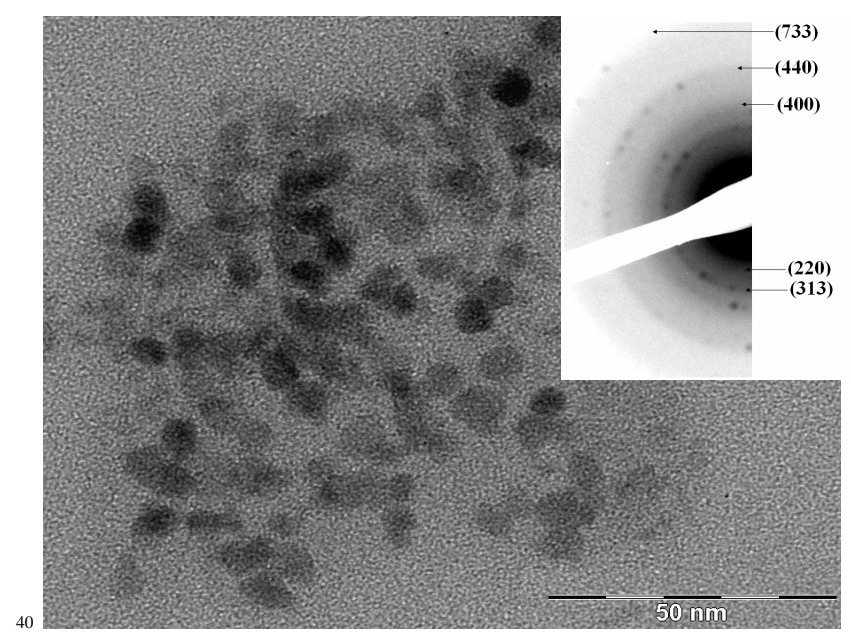

Fig. 2 TEM image of nanoparticles prepared in the channel (for flow rates $\mathrm{Q}_{\text {in }}=100 \mu \mathrm{l} / \mathrm{min}$ and $\mathrm{Q}_{\text {out }}=400 \mu \mathrm{l} / \mathrm{min}$ ). The inset shows the electron microdiffraction pattern with the Miller indices of $\gamma-\mathrm{Fe}_{2} \mathrm{O}_{3}$
Samples for Transmission Electron Microscopy (TEM) 45 were prepared by placing a single drop of the resulting suspension onto a 200 mesh holey carbon-coated copper grid (SPI) which was then allowed to dry in air. The suspensions obtained by $\mathrm{Fe}(\mathrm{II}) / \mathrm{Fe}$ (III) coprecipitation were also analysed by Vibrating Sample Magnetometry (VSM).

${ }_{50}$ As the flow of TMAOH was fixed $\left(\mathrm{Q}_{\text {out }}=400 \mu \mathrm{l} / \mathrm{min}\right)$ and the volumetric flow of the iron precursors mixture was increased $\left(10<\mathrm{Q}_{\text {in }}<100 \mu \mathrm{l} / \mathrm{min}\right)$, colour changed from brown to black, characteristic of magnetite $\mathrm{Fe}_{3} \mathrm{O}_{4}$. The suspensions obtained in cyclohexane are always stable. However, Dynamic Light ${ }_{55}$ Scattering (DLS) measurements of the aqueous solutions showed that the colloidal suspension exhibits the lowest hydrodynamice size $\left(\mathrm{d}_{\mathrm{H}}=120 \mathrm{~nm}\right)$ for a ratio $\mathrm{Q}_{\text {out }} / \mathrm{Q}_{\text {in }} \sim 4$. TEM observation of the colloidal suspension in cyclohexane indicated that the nanoparticles produced in the channel are 60 fairly spherical with an average size around $7 \mathrm{~nm}$. The evidence of their cristallinity is provided by the electron microdiffraction pattern in the inset of Fig. 2, which shows the presence of the maghemite phase $\gamma-\mathrm{Fe}_{2} \mathrm{O}_{3}$.

Although suspensions obtained in cyclohexane are stable in 65 zero magnetic field. They sediment in the presence of a magnetic field gradient (for example on a strong permanent magnet), which suggests a magnetic character. This observation agrees with the VSM measurement on a stable unquenched (aqueous) suspension: the magnetization curve 70 (Fig. 3) follows the Langevin law typical of superparamagnetism, calculated for an assembly of nanoparticles with a rather narrow distribution of diameters fitted by a Log-normal law of parameters $\mathrm{d}_{0}=6 \mathrm{~nm}$ and $\sigma=0.2$. The particles size deduced from the analysis of the 75 magnetization curve shape are in good accordance with the TEM pictures.

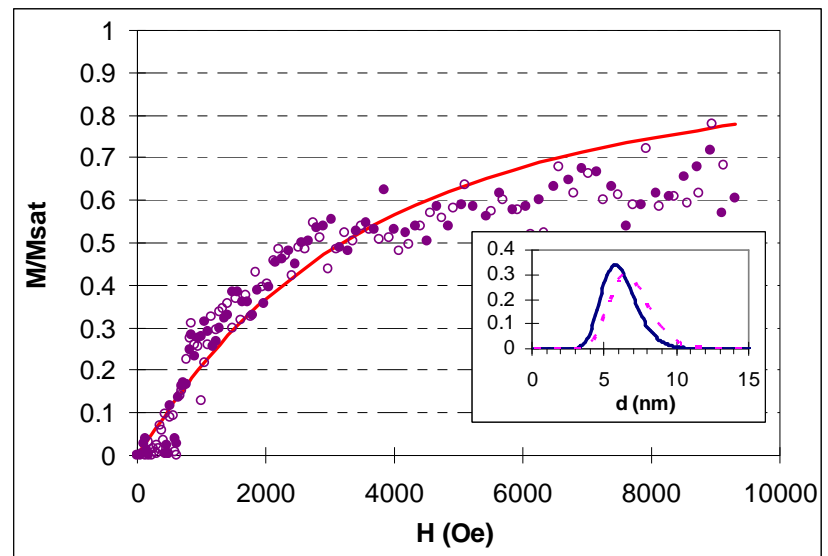

Fig. 3 Magnetisation curve of a stable suspension in water of nanoparticles produced in the millifluidic device. The inset curves 80 represent the fitting Log-normal laws for the numbers distribution (solid line) and the volume distribution (dotted line) of diameters.

By measuring both the volume fraction of nanoparticles $\phi=5.7 \times 10^{-5}$ (from iron titration by atomic spectroscopy) and the saturation magnetization $\mathrm{M}_{\mathrm{sat}}=7.9 \mathrm{~A} / \mathrm{m}$ for the suspension, 85 we deduce a specific magnetization $\mathrm{m}_{\mathrm{s}}=\mathrm{M}_{\mathrm{sat}} / \phi=1.4 \times 10^{+5} \mathrm{~A} / \mathrm{m}$ for the materials, which is much below the bulk value of maghemite $\gamma-\mathrm{Fe}_{2} \mathrm{O}_{3}\left(3.5 \times 10^{+5} \mathrm{~A} / \mathrm{m}\right)$, but not so far from the $\mathrm{m}_{\mathrm{s}}$ 
value about $2.6 \times 10^{+5} \mathrm{~A} / \mathrm{m}$ usually obtained for nanoparticles of approximatively the same sizes prepared with the standard large scale synthesis. $^{23}$ Therefore we can deduce that compared to classical ones, nanoparticles prepared within few 5 seconds in a millifluidic channel exhibit only a small decrease of ordering of their magnetic moments.

We have demonstrated that aqueous dispersions of superparamagnetic iron oxides nanoparticles can be prepared on chip in a millichannel reactor by providing a cylindrical 10 geometry of the device and the use of TMAOH as alcaline reagent. These results open the way to other experiments such as online fonctionnalization, online detection and structural measurements of the nanoparticles. A further miniaturization of the channels would enhance the time resolution and enable 15 kinetic studies of the coprecipitation mechanism.

\section{Aknowlegdments}

We would like to thank Dr. Hervé Willaime from 20 "Microfluidics, MEMS \& Nanostructures" (MMN) laboratory at ESPCI, France and Dr. Caroline Derec, from "Matières et Systèmes Complexes" (MSC) laboratory at Univ Paris 07, France for their very fruitful discussions at the beginning of this work. We thank also Patricia Beaunier from the Service 25 de Microscopie Electronique de Paris 6 for TEM images.

\section{Notes and references}

${ }^{a}$ Laboratoire Liquides Ioniques et Interfaces Chargées (LI2C), UMR7612 UPMC Univ Paris 06 / CNRS / ESPCI, Université Pierre et Marie Curie, 304 place Jussieu, case 5175252 Paris cedex 5, France. Fax: +33 (1) 44273228; Tel: +33 (1) 44273166; E-mail: abouhas@ccr.jussieu.fr ${ }^{b}$ Laboratoire "Microfluidics, MEMS \& Nanostructures" (MMN), UMR7083 CNRS / ESPCI, Ecole Supérieure de Physique et de Chimie Industrielles de Paris, 10 rue Vauquelin 75231 Paris cedex 5, France

1. M. Tokeshi, T. Minagawa, K. Uchiyama, A. Hibara, K. Sato, H. Hisamoto and T. Kitamori, Anal. Chem., 2002, 74, 1565.

2 J. Klaus, H. Volker, L. Holger and B. Manfred, ChemInform, 2004, 35.

403 K. F. Jensen, Chem. Eng. Sci., 2001, 56, 293.

4. A. J. DeMello and J. C. DeMello, Lab. Chip, 2004, 4, 11N.

5. S. Sun and H. Zeng, J. Am. Chem. Soc, 2002, 124, 8204

6. R. Massart, E. Dubois, V. Cabuil and E. Hasmonay, J. Magn. Magn. Mater, 1995, 149; A. Bee, R. Massart and S. Neveu, J. Magn. Magn.

45 Mater., 1995, 149, 6; O. Sandre, J. Browaeys, R. Perzynski, J. C. Bacri, V. Cabuil and R. E. Rosensweig, Phys. Rev. E, 1999, 59, 1736; M. Racuciu, D. E. Creanga, G. J. Calugaru, J. Optoelectron. Adv. Mater., 2005, 7, 2859

7. M. S. Martina, J. P. Fortin, C. Menager, O. Clement, G. Barratt, C.

50 Grabielle-Madelmont, F. Gazeau, V. Cabuil and S. Lesieur, J. Am. Chem. Soc., 2005, 127, 10676; W. J. M. Mulder, G. J. Strijkers, G. A. F. Van tilborg, A. W. Griffioen and K. Nicolay, NMR. Biomed., 2006, 19.

8. J. P. Fortin, C. Wilhelm, J. Servais, C. Menager, J. C. Bacri and F. 55 Gazeau, J. Am. Chem. Soc., 2007, 129, 2628

9. V. K. LaMer and R. H. Dinegar, J. Am. Chem. Soc, 1950, 72, 4847; V. K. LaMer, Ind. Eng. Chem., 1952, 44, 1270.

10. P. Jongnam, J. J. Soon, G. K. Youngjin and J. T. Hyeon, Angew. Chem., Int. Ed., 2007, 46, 4630.

60 11. J. B. Edel, R. Fortt, J. C. deMello and A. J. deMello, Chem. Commun., 2002, 1136.

12. H. N. H. Wang, M. Uehara, Y. Yamaguchi, M. Miyazaki, and H. Maeda, Adv. Funct. Mater., 2005, 15, 603; A. G. B. K. H. Yen, M.
A. Schmidt, K. F. Jensen and M. G. Bawendi, Angew. Chem., Int. 65 Ed. , 2005, 44, 5349; H. Wang, X. Li, M. Uehara, Y. Yamaguchi, H. Nakamura, M. Miyazaki, H. Shimizu and H. Maeda, Chem. Commun., 2004, 48; E. M. Chan, R. A. Mathies and A. P. Alivisatos, Nano Lett., 2003, 3, 199.

13. S. A. Khan, A. Gunther, M. A. Schmidt and K. F. Jensen, Langmuir, 2004, 20, 8604.

14. H. Wang, H. Nakamura, M. Uehara, M. Miyazaki and H. Maeda, chem. comm., 2002, 1462; B. F. Cottam, S. Krishnadasan, A. J. DeMello, J. C. DeMello and M. S. P. Shaffer, Lab. Chip, 2007, 7, 167.

75 15. S. A. Khan and K. F. Jensen, Adv. Mater., 2007, 19, 2556.

16. R. Massart and V. Cabuil, J. Chim. Physi., 1987, 7, 84.

17. V. P. Andreev, S. B. Koleshko, D. A. Holman, L. D. Scampavia and G. D. Christian, Anal. Chem. 1999, 71, 2199.

18. J. B. Knight, A. Vishwanath, J. P. Brody and R. H. Austin, Phys. Rev. Lett., 1998, 80, 3863.

19 Estimated from Einstein-Stokes equation $\mathrm{D}=\mathrm{kT} / 6 \pi \eta \mathrm{r}$, with $\mathrm{T}=25^{\circ} \mathrm{C}$, $\eta=1 \times 10^{-3} \mathrm{~Pa} . \mathrm{s}$ and $\mathrm{r}=2.060 \mathrm{~A}^{\circ}$ and reference 20

20 R. L. Martin, P. J. Hay and L. R. Pratt, J. Phys. Chem. A, 1998, 102, 3565

8521 E. L. Cussler, Diffusion Mass Transfer in Fluid Systems, Cambridge University Press, Cambridge, $2^{\text {nd }}$ edn, 1997, pp 143

22 G. Mériguet, E. Dubois and R. Perzynski, J. Colloid. Interf. Sci, 2003, 267, 78.

23. F. Gazeau, E. Dubois, M. Hennion, R. Perzynski, Y. Raikher, Eur. $90 \quad$ Phys. Lett. 1997, 40, 575.

Electronic supplementary information (ESI) available: COMSOL Multiphysicss simulations and focusing defocusing images. See DOI: 10.1039/b719550h 
Focusing and de-focusing transition depending on the ratio $Q_{\text {out }} / Q_{\text {in }}$ where $Q_{\text {out }}=0.1 \mathrm{ml} / \mathrm{min}$ and $0.250<Q_{\text {in }}<3 \mu \mathrm{l} / \mathrm{min}$

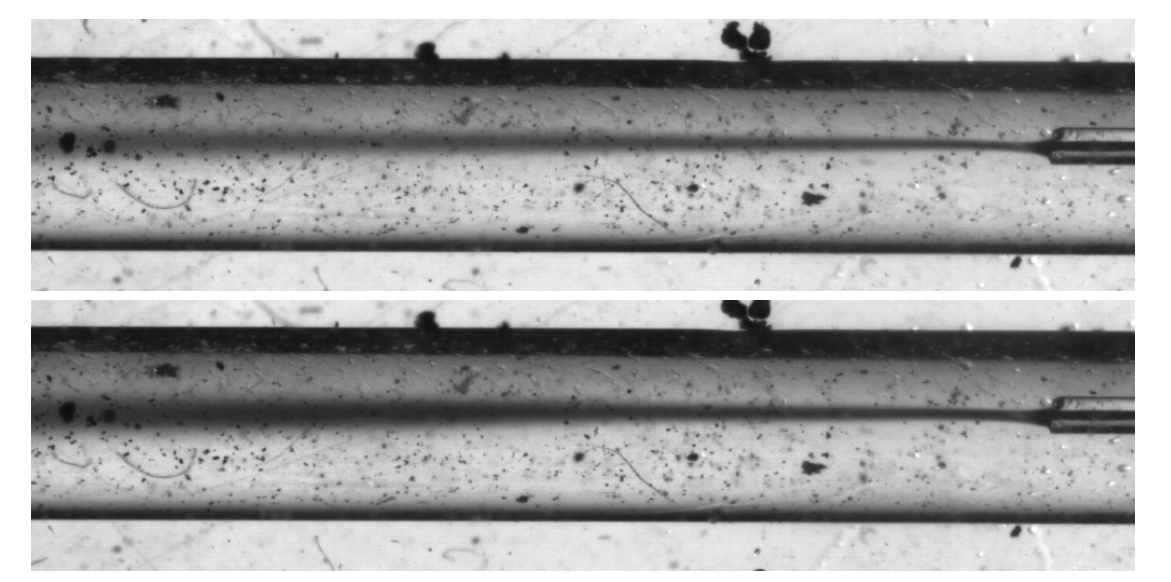

$$
\mathrm{Q}_{\text {in }} / \mathrm{Q}_{\text {out }}=400
$$

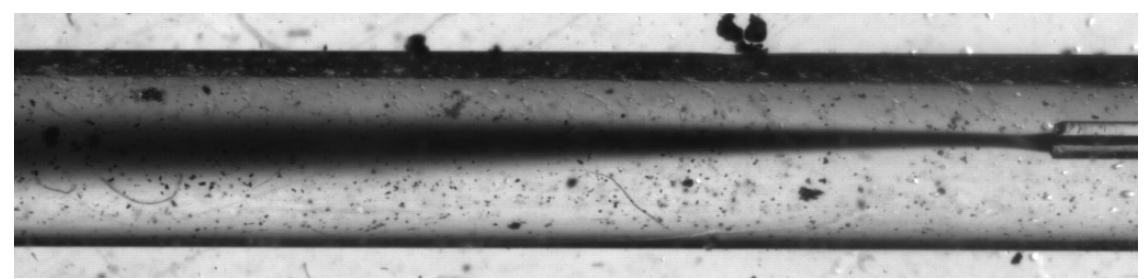

$$
Q_{\text {in }} / Q_{\text {out }}=200
$$

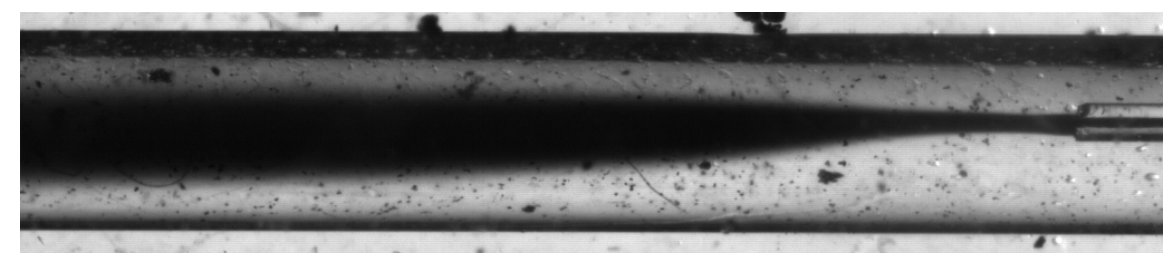

$$
Q_{\text {in }} / Q_{\text {out }}=100
$$

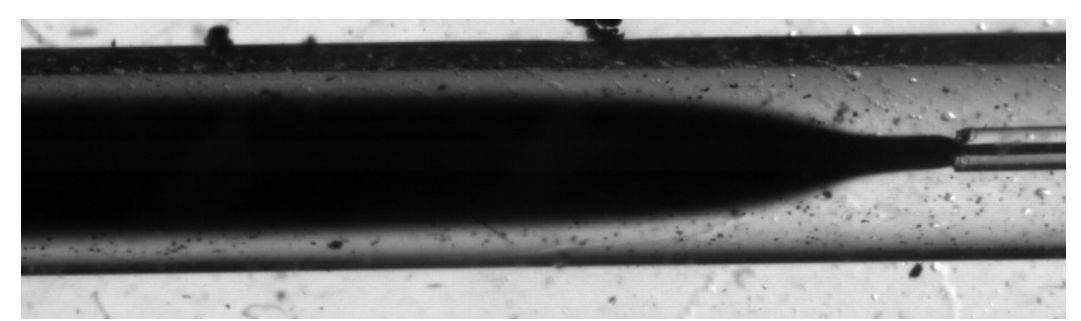

$Q_{\text {in }} / Q_{\text {out }}=33$ 


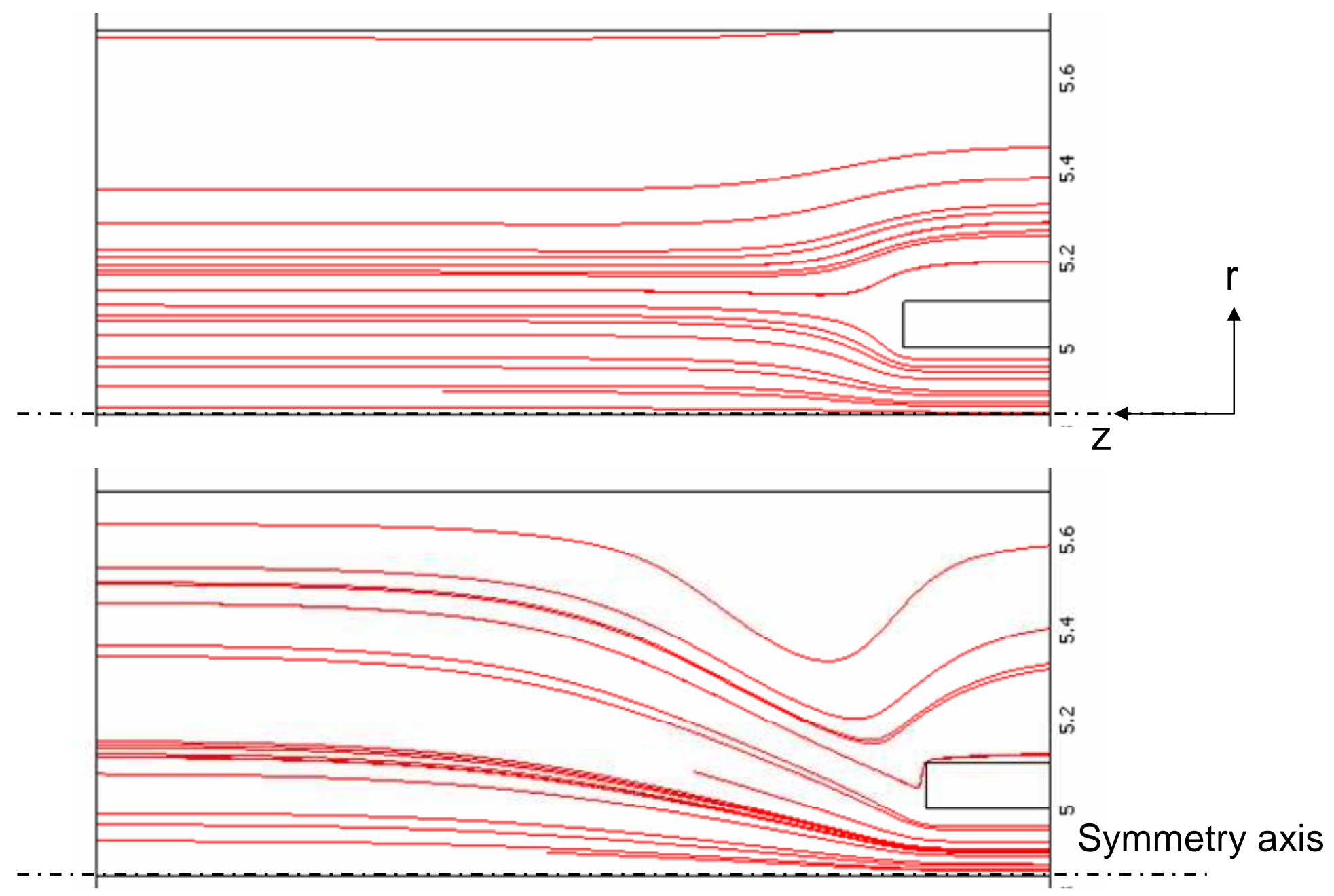

2D axisymmetric COMSOL Multiphysics ${ }^{\circledR}$ simulations of the velocity streamline in the millichannel, where $Q_{\text {out }}=400 \mu \mathrm{l} / \mathrm{min}$ and a) $Q_{\text {in }}=10 \mu \mathrm{l} / \mathrm{min} ; \quad$ b) $Q_{\text {in }}=100 \mu \mathrm{l} / \mathrm{min}$ 